\title{
Complutum
}

ISSN: 1131-6993

\section{El necesario cambio de modelo en la Arqueología profesional española ${ }^{1}$}

\author{
Ignacio Rodríguez Temiño²; José Andrés Afonso Marrero ${ }^{3}$
}

Recibido: 07 de junio de 2018 / Aceptado: 25 de abril de 2019

Resumen. Los arqueólogos profesionales son aquellas personas que viven del ejercicio liberal de la Arqueología. Resulta preocupante que se haya convertido en un tópico señalar que la Arqueología profesional está en crisis. Las causas podrían resumirse en tres. En primer lugar, sus practicantes desempeñan un difícil papel intermedio entre las administraciones culturales, por un lado, y los promotores, por otro. De la primera dependen para desarrollar las actividades que son encargadas por los segundos, quienes lo hacen no por convicción sino para satisfacer las obligaciones impuestas normativamente. Una segunda causa de insatisfacción procede de la dejación, por parte de las administraciones culturales, de algunas de las responsabilidades sobre la Arqueología preventiva en manos de los promotores y propietarios de suelo, como aplicación del neoliberalismo más descarnado. Por último, la relación con la administración cultural normalmente resulta fluida, pero ello no evita los tiempos, en muchas ocasiones inexplicables, que la burocratización ha impuesto para culminar trámites, como el de las autorizaciones de actividades arqueológicas. En este trabajo identificamos estas tres circunstancias como el problema de la Arqueología profesional y la causa del malestar de quienes la practican, pero también proponemos una solución para resolver esos desajustes que, lejos de ser coyunturales, se han vuelto sistémicos en la gestión de la Arqueología preventiva y, por tanto, imposibles de atajar si no se cambia de modelo.

Palabras clave: Arqueología profesional; Arqueología preventiva; gestión patrimonio arqueológico; Arqueología urbana.

\section{[en] The necessary change of model in the spanish professional archaeology}

Summary. Professional archaeologists to be people who make their living through the practice of archaeology. In this regard, it has become disturbingly commonplace to note that professional archaeology is in crisis. The reasons are threefold. First, its practitioners play a difficult intermediate role between cultural authorities, on the one hand, and developers, on the other. They depend on the former to carry out the activities commissioned from them by the latter, who, in turn, commission those activities not out of conviction, but to meet their legal obligations. The second cause of dissatisfaction stems from the fact that cultural authorities have handed over some of their responsibilities for preventive archaeology to developers and landowners, in an example of stark neoliberalism. Finally, although the relationship with cultural authorities is usually fluid, that does not prevent bureaucratization from imposing often inexplicable deadlines for processing formalities such as permits for archaeological activities.

In this paper, we identify these three circumstances as the problem facing professional archaeology and the cause of the malaise affecting its practitioners. However, we also propose a solution to address these challenges, which, far from temporary, have become systematic in the management of preventive archaeology and, therefore, impossible to check without a change of model.

Keywords: Professional Archaeology; Preventive Archaeology; Archaeological Heritage Management; Urban Archaeology.

Sumario: 1. Introducción. 2. Evolución reciente de la Arqueología profesional. 3. El malestar de la Arqueología profesional en España. 4. Una propuesta de solución al malestar de los arqueólogos profesionales. 5. Referencias bibliográficas.

Este artículo ha sido posible gracias a la ayuda del Proyecto I+D+i DER2016-74841-R: 'Instrumentos jurídicos en defensa de la integridad de los bienes arqueológicos', financiado por el Ministerio de Economía y Competitividad para el periodo 2017-2019.

2 Consejería de Cultura y Patrimonio Histórico, Junta de Andalucía . Némesis. Asociación para la Investigación y Defensa del Patrimonio Arqueológico contra el Expolio y el Tráfico Ilícito. ignacio.rodriguez.temino@juntadeandalucia.es

3 Departamento de Prehistoria y Arqueología, Universidad de Granada jaamarre@ugr.es 
Cómo citar: Rodríguez Temiño, I.; Afonso Marrero, J. A. (2019): El necesario cambio de modelo en la Arqueología profesional española. Complutum, 30(1): 43-57.

\section{Introducción}

Los profesionales son una categoría laboral que goza de un enorme prestigio social. Desde su proliferación tras la segunda guerra mundial, han sido la avanzada y sostén del desarrollo industrial y tecnológico de la sociedad y de su estado de bienestar. Ser profesional es garantía de rigor, seriedad y eficacia, por ello reciben reconocimiento y emolumentos en consonancia.

En el mundo de la Arqueología, existen profesionales sensu lato distribuidos laboralmente en tres ámbitos. El universitario y de centros de investigación; las administraciones competentes en la gestión del patrimonio arqueológico y museos; $y$, finalmente, quienes la ejercen como profesión liberal, o bien son trabajadores por cuenta ajena en empresas relacionadas con este sector y en las que ejercen funciones de arqueólogo. En este último grupo consideramos que deberían incluirse no solo aquellas personas y empresas relacionadas con la Arqueología preventiva, sino también las que lo están con la difusión, la interpretación, la animación cultural y la educación, siempre que su actividad esté especializada en el patrimonio arqueológico.

Sin embargo, este artículo, que versa sobre este último ámbito laboral, los excluye y se dirige concretamente a quienes desempeñan su trabajo en Arqueología preventiva a través de actividades arqueológicas, entendidas en la forma en que estas están recogidas en la legislación sobre patrimonio histórico y cultural. La razón de la exclusión de quienes trabajan en difusión del patrimonio arqueológico es bien fácil: la problemática a que está sujeta la Arqueología preventiva presenta unas peculiaridades específicas en el terreno laboral, ajenas al de otras personas y empresas dedicadas a la difusión o la educación.

Antes de continuar debemos acotar mejor el ámbito de profesionales objeto de este trabajo. Ya se ha aclarado que son los que se dedican a la Arqueología preventiva, pero se aplica mejor a quienes lo hacen de forma autónoma y no como técnicos asalariados en empresas de Arqueología (Díaz del Río 2000, Ad'AC 2000, Moya Maleno 2010). Por tanto, cuando se utilice la expresión «Arqueología profesional» es para referirnos a estas personas. En España el número de arqueólogos autónomos es bastante mayor que el de asalariados en empresas.

En realidad, el uso del término profesional referido a la Arqueología se ha entendido así casi desde el principio fuera de España (Dalwood, 1987). Si bien en nuestro entorno se ha cuestionado ese empleo por redundante (Querol 2000: 355 s.), ya que implicaría la existencia de una Arqueología no profesional. Esto nos aboca a explicar qué entendemos por ese concepto.

Cuando se usa el epíteto «profesional» para designar a aquella persona que ejerce una profesión, resulta evidente que en los tres ámbitos señalados se encuentran profesionales de la Arqueología. Sin embargo, creemos en la existencia de un significado más restringido de ese término, aplicable a quienes han transformado sus conocimientos especiales en unas competencias. Esto es en su aplicación creativa y flexible para resolver problemas y contingencias, es decir lo han convertido en conocimiento experto. En esto se diferencian de quienes tienen otro estatuto con respecto al saber, como puedan ser los especialistas, cuya principal fuente de conocimiento es la investigación de campo y gabinete referida a problemas de índole histórico-arqueológica. Frente a ellos, lo específico de los profesionales es que la práctica les enfrenta a diversos retos no previstos en su formación teórica, cuya solución requiere del uso creativo de conocimientos previos, reflexión y evaluación de los resultados. Para conseguir dicho objetivo, los profesionales deben alcanzar el nivel de experto en los términos definidos por H. Dreyfus y S. Dreyfus (1986). Este conocimiento experto se caracteriza por la integración de diversos saberes y prácticas que Tynjälä resume en: un amplio conocimiento formal en la materia, la aplicación práctica de dichos conocimientos a la solución de problemas y el conocimiento auto-regulativo, entendido como la habilidad que permite a las personas gestionar y evaluar sus acciones (Tynjälä 1999: 359).

Esto no significa que enucleemos el dominio de la teoría del perfil profesional: para aprender con y en la práctica se requieren instrumentos de naturaleza conceptual que faculten para interpretar reflexivamente qué, cómo 
y para qué se hacen ciertas cosas o adoptan determinadas decisiones, en detrimento de otras posibilidades. Es lo que David Barreiro ha denominado como tecnociencia (Barreiro Martínez 2013: 106 ss.).

También queremos dejar claro que no nos referimos en exclusiva a profesionales de la excavación o de las actividades arqueológicas, sino a quienes usan sus conocimientos en Arqueología -pero no solo estos- y sus experiencias previas para enfrentarse a problemas de tutela del patrimonio arqueológico de índole compleja. En ellos se confrontan intereses legítimos contrapuestos y en cuya solución deben encontrar acomodo a todos ellos -o al menos a los más relevantes- haciendo uso de una racionalidad técnica que aúna teoría y práctica (Barreiro Martínez 2013: 65 ss.). Su ámbito de actuación profesional no solo afecta, pues, a las actividades arqueológicas preventivas, sino también al asesoramiento en restauración, al manejo de técnicas particulares aplicadas a la Arqueología, la planificación urbanística y territorial o las evaluaciones de impacto ambiental, por citar situaciones habituales.

En todo caso, resulta evidente que, desde esta significación acotada del término «profesional», el mundo académico, caracterizado por su labor relacionada con la docencia e investigación en Arqueología, queda apartado del ámbito de la subdisciplina «Arqueología profesional» explicado aquí. Otro tanto podría decirse de quienes trabajan en la actualidad en centros administrativos, donde su quehacer en relación con la tutela del patrimonio arqueológico sigue protocolos estandarizados.

De la explicación dada en el párrafo anterior no cabe pensar que esas diversas áreas sean estancas y no compartan espacios comunes, como parece deducirse de algunos puntos de vista (Martín-Bueno 2018). Antes bien, la protección, conservación, investigación y difusión del patrimonio arqueológico son tareas que, en diverso grado, comparten todas las personas que se dedican a la Arqueología de forma transversal. En este sentido, se han dado situaciones, en la década de los ochenta del pasado siglo, en que personas del mundo académico y administrativo hubieron de realizar una actuación característicamente profesional cuando se vieron en la tesitura de crear, casi de la nada, un sistema coherente para gestionar el patrimonio arqueológico (Fernández-Miranda 1985, Ruiz Rodríguez 1989, Rodríguez Temiño 2004).
En realidad, los profesionales no solo se enfrentan a imprevistos o deben solucionar situaciones complejas, sino que expresan todo su potencial cuando identifican los propios problemas, a través del análisis reflexivo de la realidad sobre la que operan (Schön, 1983: 40). No obstante, no son infrecuentes las ocasiones en que la rutina administrativa y profesional erosiona todo interés en la adquisición de formación significativa con la práctica (Rodríguez Temiño 2001, Álvarez Martínez 2011).

En la literatura relativa a la Arqueología preventiva, también denominada «Arqueología comercial» aunque no nos agrade especialmente ese apelativo, se está consolidando un tipo de texto en el que se narra las experiencias de personas que encajan en la idea de Arqueología profesional expuesta aquí (véanse, por ejemplo, Marín Suárez 2011, Everill 2012, Aitchison 2012, Berrocal Ruiz 2014 o Almansa Sánchez 2017).

Aclarado este primer concepto, queremos recordar que la gran recesión iniciada en 2007 ha afectado a todo el mundo laboral, pero sin duda el golpe ha sido más dramático en las profesiones vinculadas con la construcción. En la Arqueología profesional española, el pinchazo de la burbuja inmobiliaria ha tenido unas consecuencias específicas que van más allá de la pérdida de trabajo y el cierre de empresas del sector, como ha ocurrido en el resto de países (Parga Dans 2010, Aitchison 2012: posiciones 63 a 73).

En efecto, aunque sea habitual, refiriéndose al caso hispano, hablar de crisis del sector, en nuestra opinión la Arqueología española no lo está. Las crisis son coyunturas traumáticas de tránsito entre dos etapas distintas. La Arqueología profesional española atraviesa una etapa laboral malísima, pero estable. Y, desgraciadamente, sin perspectivas de cambio. No nos referimos a una mejora en las oportunidades de negocio que, por fortuna, comienzan a ser más frecuentes, sino al problema que acarrea desde su origen, como si fuese una especie de pecado original: el carácter de «falsos» profesionales de quienes se dedican a ella. Trabajar sobre unos bienes objeto de una tutela intensiva por parte de la administración, como hacen los arqueólogos, limita las posibilidades del ejercicio profesional autónomo y el alcance de las propuestas que puedan arbitrarse en relación a los problemas que plantean sus clientes. Además, el destino social del patrimonio arqueo- 
lógico conlleva unas decisiones que frecuentemente van contra los intereses más inmediatos de quienes les contratan. Lo cual tampoco se compadece bien con la relación habitual entre profesionales y clientes.

La razón de la perduración del problema de la Arqueología profesional es su carácter sistémico y no contingente. En la pasada época de bonanza durante el «boom del ladrillo» se tomaron, o al menos fueron adoptadas de forma generalizada, determinadas decisiones que escondían el desajuste del encaje anormal de la participación del sector profesional en el desarrollo de la Arqueología preventiva. La razón de este desajuste reside en la tensión entre la tutela administrativa del patrimonio arqueológico y la financiación privada de las actuaciones preventivas sobre él. Esto deja en una situación intermedia e indefinida, por no estar bien regulada, la participación de los profesionales, o de las empresas, en ese proceso. Sin embargo, esos inconvenientes no salieron a flote. La exuberante oferta de trabajo y la dinámica de gestión de excavaciones, guiada por la prisa para no obstaculizar la inversión en construcción e infraestructuras, actuaron como lenitivo que impidió el afloramiento de las contradicciones del sistema. Por otra parte, las tensiones con la Arqueología «universitaria» sirvieron igualmente para desviar una mirada introspectiva sobre el propio colectivo profesional.

La recesión económica y la caída en picado de la frenética carrera de intervenciones preventivas han desvelado este problema sistémico, cuya manifestación más evidente -a nuestro juicio- es la génesis del sentimiento complejo de desesperanza y desasosiego que caracteriza, en buena medida, la percepción de su quehacer que tienen muchos profesionales de la Arqueología preventiva (por ejemplo, Álvarez Martínez 2011).

En el I Encuentro Estatal de Arqueología Profesional celebrado en Cádiz en el mes de noviembre de 2018, organizado por el Colegio de Doctores y Licenciados en Ciencias y Letras (CDL) de Cádiz, pareció constatarse que posiblemente los efectos más severos de la crisis en la Arqueología preventiva hayan pasado ya, pero el malestar de la Arqueología profesional no va a ser tan pasajero. Ese encuentro ha tenido continuidad en otro realizado en Madrid, como iniciativa del CDL de Madrid, en el mes de abril de 2019, cuya tónica por lo que conocemos ha sido coherente con la de Cádiz. Y se espera otro en Zaragoza en fechas próximas.
Este trabajo trae causa de esta línea de encuentros, pero no es una crónica de lo sucedido ni representa el parecer del conjunto de asistentes a ellos, aunque la propuesta que presentamos se debatiese en el de Cádiz y estuviese también en Madrid.

Sin embargo, tanto en uno como en otro, se abordaron los problemas que conlleva la práctica de la Arqueología profesional junto a otra variada casuística situada extramuros de ella, en una mezcolanza de criterios y finalidades poco operativa, en nuestra opinión. $\mathrm{Y}$ eso es lo que nos resulta preocupante. En efecto, cuando se escuchan propuestas concretas, cuya bondad o necesidad no cuestionamos, como que los arqueólogos profesionales tengan un epígrafe específico en el Impuesto de Actividades Económicas y, a renglón seguido, sobre cuál es la idea que tiene la sociedad de la Arqueología, no podemos dejar de pensar que los árboles no dejan ver el bosque; que a la Arqueología profesional le pasa que no se sabe qué le pasa. Por tal motivo, nos parece relevante explicar nuestra idea de la Arqueología profesional, a pesar que ninguno de nosotros la ejerce. Sin embargo, sí hemos venido reflexionando sobre ella, sobre la base de nuestro conocimiento directo del sector, para nuestras clases en el máster interuniversitario en Arqueología de las universidades de Sevilla y Granada, donde impartimos docencia en una asignatura que dedica buena parte del tiempo a explicar una aproximación a la Arqueología profesional. Tampoco resulta baladí tomar en consideración que las personas egresadas de las universidades, que quieran dedicarse a la Arqueología, debieran tener en el ejercicio de la Arqueología profesional una salida digna que no sea sinónimo de precariedad o frustración (Aparicio Resco 2018: 19 ss.).

No se nos escapa que los problemas de la Arqueología preventiva van más allá del estatuto y situación de los profesionales (Querol 2000, Rodríguez Temiño 2010a y 2010b, Ribera i Lacomba 2015, Vaquerizo Gil 2018), cuya resolución requiere asimismo de medidas urgentes. Sin embargo, obviaremos esas cuestiones aquí para hacer más nítida nuestra propuesta. La Arqueología profesional es un sector indispensable en la gestión de la Arqueología preventiva, su malestar es el de la propia gestión del patrimonio arqueológico. Sin su participación entusiasta resulta impensable que la Arqueología se convierta en la presta- 
ción social a la que el ordenamiento jurídico la convoca.

Por ello consideramos que debe acometerse este problema con presteza, sobre todo ahora que la recesión ha servido no solo para reducir el número de quienes realizaban excavaciones, sino también para depurar a los auténticos profesionales vocacionales de quienes se acercaron por la facilidad de ganar un sustento (Aitchison 2012: posición 201). No obstante, volvemos a insistir en que, posiblemente, se identifiquen menos con la propuesta que emana de este trabajo quienes prestan su servicio como arqueólogos por cuenta ajena en empresas de Arqueología, ya que normalmente no son quienes exteriorizan y defienden las decisiones adoptadas en relación al patrimonio arqueológico sobre el que trabajan, pero no hay voluntad de excluir a nadie. Para regular las condiciones laborales de este colectivo la figura idónea será la del convenio colectivo del sector, reivindicación que ha estado encima de la mesa en diversas ocasiones (Ad'AC 2000, CNT-Córdoba 2010).

Para identificar el problema que atenaza a la Arqueología profesional, primero debe reflexionarse sobre cómo se ha llegado hasta aquí, para después proponer una vía de solución que, sin ser la panacea, al menos contribuya a mejorar su encaje sistémico en la gestión de la Arqueología preventiva.

\section{Evolución reciente de la arqueología profesional}

El desarrollo de una Arqueología profesional ha sido, sin duda, uno de los aspectos más novedosos que ha traído como consecuencia la generalizada implantación de la Arqueología preventiva.

El surgimiento y avatares por los que ha pasado, desde finales de la década de los setenta del pasado siglo hasta la actualidad, ha sido objeto reiterado de estudio (Salvatierra Cuenca 2004 y 2013, Rodríguez Temiño 2004: 216 ss., Roig i Buxó 2013, Morín de Pablos y Barroso Cabrera 2014, Almansa Sánchez 2017, Vaquerizo Gil 2018: 179 ss.), lo cual nos ahorra aquí hacer una descripción detallada de los pormenores de este proceso. Para facilitar la explicación se dividirán los casi cuarenta años de Arqueología profesional en tres etapas, sin que pongamos demasiado empeño en justificar los límites de cada una ya que son flexibles.
La primera etapa es de carácter formativo y en ella se producen los primeros desarrollos. Comienza hacia 1978, cuando se celebra la primera Assemblea d'Arqueologia de Catalunya, y culmina a inicios de los noventa, al generalizarse en determinadas comunidades autónomas las empresas de Arqueología.

Debe señalarse que los primeros conatos de profesionalización de la Arqueología en España no estuvieron ligados al desarrollo de las excavaciones preventivas, como ocurrió en el Reino Unido (Dalwood 1987, Aitchison 2012: posiciones 507-625) o en Francia (Demoule 2010). En nuestro país, la mencionada Assemblea (Hernández Herrero 1992) fue un movimiento nacido con la finalidad de organizar la Arqueología en Cataluña, a raíz del traspaso de competencias. Dentro del colectivo tuvieron cabida todas las personas que eran o querían ser arqueólogas. El interés de las reuniones se centró en la investigación y su institucionalización. A finales de los setenta y comienzo de los ochenta, la Arqueología preventiva en España era virtualmente inexistente. Por tanto, a muchos de los integrantes de la Assemblea les preocupaba el futuro de sus excavaciones, financiadas hasta entonces por el Ministerio de Cultura. No era muy distinto ese interés del que movería a la Comisión Andaluza de Arqueología poco tiempo después (Rodríguez Temiño y Rodríguez de Guzmán Sánchez 1997).

Siguiendo esta misma estela, la Asociación Profesional de la Arqueología Española (APAE) (Querol 1992 y Querol et alii 1997) reunía principalmente a personas relacionadas con la docencia universitaria y la conservación museística, muy alejadas de la Arqueología preventiva. De hecho, la quiebra en la viabilidad de su propuesta inicial de Estatuto Profesional de la Arqueología (1987) se cifró en la falta de demanda social de arqueólogos, justamente cuando estaba comenzando a producirse. Lo cual demuestra la separación de la APAE con la problemática de la Arqueología preventiva.

Ambos precedentes solo tienen una relación nominativa con el surgimiento posterior de arqueólogos propiamente profesionales. Estos, además, no se sintieron herederos ni concernidos con las preocupaciones planteadas por los movimientos pioneros, sino que rápidamente expresaron su propia agenda que solo coincidía con la anterior problemática en algunos puntos concretos, sobre todo en la falta de titulación propia en Arqueología. Por tanto, 
el desarrollo de la Arqueología profesional en España no arranca de estos precedentes sino del éxito de las medidas cautelares decretadas en ámbito urbano y rural, lo que provocó la necesidad de excavaciones arqueológicas de forma desconocida hasta entonces.

Si al principio los arqueólogos que las realizaban estaban vinculados en cierta forma a las administraciones, su incremento llevó a la independencia de esos vínculos. Durante la segunda mitad de los ochenta y comienzo de los noventa, quienes dirigían las actividades preventivas eran profesionales libres agrupados en las secciones de Arqueología de los CDL creadas por ellos mismos.

A partir de los noventa aparecerán las empresas de Arqueología diversificando el régimen económico de la Arqueología profesional (Parga Dans 2009). Con ello creemos que se abrió una nueva etapa, que se cerró con la crisis económica de 2007. Aunque en esta nueva fase se multiplican los regímenes de los arqueólogos profesionales (autónomos, empresarios y asalariados), no es esta la característica principal para definir la etapa. La singularidad procede de un modo de gestionar la Arqueología preventiva que primó la competencia entre empresas para la adjudicación de las obras, el encumbramiento de los promotores en el vértice de la gestión del patrimonio arqueológico, especialmente en las ciudades, y la reducción a un papel prácticamente testimonial de las administraciones culturales. De una u otra manera, el proceso se generalizó en todas las comunidades autónomas. Se ha mencionado en alguna ocasión (Querol 2000) la existencia de dos modelos de gestión del patrimonio arqueológico, surgidos a partir de la asunción de competencias por parte de las comunidades autónomas, uno el de la Comunidad de Madrid (o «modelo Madrid») y otro el «modelo Andaluz de Arqueología». Este último estaba especialmente dirigido a propiciar un cambio en las excavaciones llevadas a cabo por los equipos de investigación universitarios y solo tangencialmente se interesó en la Arqueología preventiva, a la que siempre vio como una competencia para sus intereses (Ruiz Rodríguez 1989, Salvatierra Cuenca 1994, Rodríguez Temiño y Rodríguez de Guzmán Sánchez 1997). Mientras que el «modelo Madrid», aunque su intención inicial fuese distinta, se ha convertido en el arquetipo del sistema de gestión de la Arqueología preventiva de cor- te neoliberal, ampliamente implantado en el Estado español (Valdés Fernández 1989, Velasco Steigrad 1992, Domínguez et alii 1994, Mena, Méndez y Velasco 1997, Martín et alii 1997, Díaz del Río Español 1999 y Rodríguez Temiño 2004: 221 ss.). Solo en algunas ciudades, como Carmona (Lineros Romero 2001), un pequeño municipio en el que la política urbanística local supo aguantar la presión de los promotores urbanísticos, se ha continuado con un modelo de intervención financiado de forma íntegra con dinero público.

El arquetipo de gestión neoliberal de la Arqueología preventiva se fraguó en el Reino Unido a partir de las líneas maestras emanadas de la Planning Policy Guidance note 16th (PPG16), titulada «Archaeology and Planning», publicada por el Ministerio de Medio Ambiente (Department of Environment) en 1990 (McGill 1995: 124 ss., Everill 2012, Aitchison 2012). Estas recomendaciones animaban a que los promotores tomasen en consideración la afección de sus proyectos al patrimonio arqueológico y que, en consecuencia, se asesorasen por arqueólogos profesionales sobre la manera de evitar daños irreparables al mismo.

Como correlato de tal asesoramiento, los promotores -especialmente en la época de bonanza económica- hicieron frente a los gastos que conllevaban las excavaciones preventivas, en aplicación del principio ambientalista «the polutor pays». Esta era, en teoría, la última opción que debía adoptarse, pero se convirtió en el único medio para compaginar la edificación y el respeto al patrimonio arqueológico.

Esta asunción de las obligaciones derivadas de un principio ético en favor de preservar -al menos en forma de documentaciónaquello que iba a perderse resulta acorde con el régimen jurídico anglosajón, para el que los propietarios de los fundos lo son también de todo lo que contienen sobre y bajo tierra, incluidos los restos arqueológicos (Radin 1993). Sin duda, esta etapa supuso un importante avance con respecto a la anterior en el Reino Unido. Esta visión triunfalista (Chowne 1998, Darvill and Russell 2002, Aitchison 2012) ha dejado paso a otra más atenta a las consecuencias negativas, como la competencia entre las distintas empresas que pugnaban por llevarse el contrato con la promotora y el desmembramiento de la ciudad como único yacimiento (Fitting 1997, Raab 1997, Ayers 2002). Dado que la iniciativa era privada, la 
gestión quedaba en manos de los principales actores: promotores y arqueólogos profesionales. La administración se sitúa en un segundo plano santificando los acuerdos alcanzados entre ellos, sin capacidad para paliar los efectos negativos generados sobre el patrimonio arqueológico $\mathrm{y}$, en último término, para garantizar su uso público. Sin embargo, incluso para el liberal derecho británico, la administración tiene margen para actuar. Este aspecto resulta relevante $\mathrm{y}$, por ello, requiere cierta explicación. El respeto de la legislación británica al derecho de propiedad no resulta ilimitado, ni está inmune a cualquier intervención administrativa. Radin (1993: 10 s.) advierte de que no toda relación subjetiva de propiedad era intrínsecamente buena, sino que tal valoración moral depende de que colectivamente se vea apropiada o no. Por tanto, esta inhibición administrativa debe ser puesta en relación con el clima político neoconservador en el que vive el Reino Unido en los últimos cuarenta años, cuya afección a la gestión del patrimonio arqueológico, en particular, y cultural en general, ha sido ampliamente cuestionada (Dromgoole 2004, Everill 2012).

En cualquier caso, la respuesta de la Arqueología profesional a la demanda de intervenciones preventivas fue muy eficaz. A ella se llegó tras un considerable esfuerzo de adaptación al nuevo marco laboral (Darvill y Atkins 1991, Chitty 1999, Bishop, Collis y Hinton 1999, Aitchison 2012), pero a la postre hay dudas sobre si ha sido capaz de autorregularse de forma adecuada para impedir la competencia desleal entre las diversas empresas. También hay notables divergencias, a la hora de valorar la influencia de esa concurrencia en las condiciones laborales de las personas que trabajan en Arqueología preventiva, especialmente en quienes trabajan asalariados en empresas. Everill (2012) ofrece una visión bastante más crítica que la de Aitchison (2012).

La tercera etapa surge en 2007, aunque en algunos casos se dejase sentir a partir de 2008 cuando se acabaron grandes proyecto iniciados años anteriores, y dura hasta la actualidad. Lógicamente el elemento característico ha sido la crisis económica que estamos sufriendo.

No hace al caso ahora centrarnos en la caída de la demanda de excavaciones preventivas y las dramáticas consecuencias para el sector de la Arqueología profesional, que con tanto ahínco se había dedicado a su monocultivo (Parga Dans 2009, Schanger \& Aitchison [eds.]
2010, Álvarez Martínez 2011, Masclans Latorre 2011, Almansa Sánchez 2014 y Almansa Sánchez 2017). Sus efectos, que no han pasado del todo, han generado mayor precariedad en quienes se incorporan al mercado laboral y un futuro más incierto, que ha acentuado una cierta desesperanza, en personas que llevan a sus espaldas una larga trayectoria profesional. No sabemos si la crisis ha pasado o solo están saliendo de ella quienes nunca entraron, pero parece cierto que, en los últimos tiempos, se va recuperando la demanda de excavaciones preventivas. Con ello se alivia el dogal que atenazaba a los profesionales, que a duras penas estaban aguantando la travesía por el desierto iniciada en 2007. En el camino se han quedado muchos arqueólogos profesionales, en ocasiones excelentes, pero también es cierto que la crisis ha servido para retirar del mercado a un importante número de profesionales, ajustando oferta y demanda.

La amplia literatura sobre la Arqueología profesional producida en estos últimos cuarenta años tiene un tono innegablemente vindicativo $\mathrm{y}$, frecuentemente, expresa descontento. También abundan propuestas para mejorar la situación por la que han atravesado, pero creemos que pocas veces se ha profundizado en la naturaleza de ese malestar. A ellos dedicamos el siguiente apartado.

\section{El malestar de la Arqueología profesional en España}

Se advierte, pues, la similitud de procesos entre el Reino Unido (y otros países de nuestro entorno) y España a lo largo de todo este tiempo de emergencia y maduración de la Arqueología profesional. Los principales actores han desempeñado también roles análogos. Al auspiciar un modelo neoliberal en España, se introdujo la semilla del problema que vive la Arqueología profesional española y que, en nada, es comparable con el anglosajón puesto que los marcos jurídicos no son equiparables. En efecto, mientras que los distintos órganos que hacen las veces de administración cultural en el Reino Unido se limitaban a respaldar o, en todo caso, a sugerir modos de hacer y procedimientos, en España la legislación otorga a las administraciones un haz de competencias sobre patrimonio arqueológico que son irrenunciables. Es más, mientras que se propagaba el modelo neoliberal de gestión descrito más 
arriba, las administraciones autonómicas y, en ocasiones también las locales, publicaron un complejo entramado de normas, tanto leyes como otras de índole infralegal, de obligado cumplimiento, especialmente para los profesionales de la Arqueología. Algo que carece de paralelo en el Reino Unido. Esta red normativa, en no pocos casos caprichosa, ata la libertad de acción de los profesionales que quedan atrapados entre dos frentes. De un lado, sus obligaciones legales, es decir su responsabilidad ante la sociedad de la que tienen que dar cuenta ante la administración. De otro, su servicio al cliente, que impone otras obligaciones distintas. El problema se agudiza porque los promotores tienen capacidad de presión sobre los arqueólogos a los que han contratado, pero estos tienen poco margen para flexibilizar una normativa cada vez más exigente (Roig i Buxó 2013). El único escenario idílico es que no aparezca nada en el subsuelo, lo cual no es habitual. Incluso ha sido objeto de suspicacias la agilidad y velocidad con que se realizan las excavaciones, siendo señalados los profesionales como responsables de muchos desmanes acaecidos en excavaciones preventivas o de urgencia, con nula empatía hacia el constreñido marco de actuación en el que intervienen (Ribera i Lacomba 2015, Vaquerizo Gil 2018, Martín-Bueno 2018).

En definitiva, nos encontramos que muchos arqueólogos liberales viven una situación esquizofrénica ya que, en realidad como se ha mencionado, son «falsos» profesionales de la Arqueología, porque el escenario les ha conducido a ser profesionales de la liberación de solares (Rodríguez Temiño 2010a). Circunstancia que afecta incluso a proyectos de Arqueología respaldados por los ámbitos administrativo y académico (CNT-Córdoba 2011), aunque se niegue por parte de los implicados (Vaquerizo Gil 2018: 386 ss.).

La Arqueología urbana suele llevar a situaciones en las que difícilmente se produce una salida de tipo "win-win», donde promotores, de un lado, y la preservación e investigación de los vestigios arqueológicos, de otro, salgan beneficiados a partes iguales. Lo más habitual es que los resultados de las actuaciones profesionales solo tengan un éxito relativo. Es lo que podría denominarse como «Kobayashi Maru», siguiendo la terminología popularizada por la saga Star Trek ${ }^{1}$. Es decir, escenarios en los que solo sacan beneficio los promotores (que identificamos con los klingon). Esa ausencia de ga- nancia, para el caso del interés público, deriva de la excepcionalidad de los supuestos en los que se contempla una conservación y musealización de vestigios acorde a su naturaleza y, para colmo, la dificultad del procesamiento de la información recogida durante la intervención para que pase al circuito académico.

Para más inri, la administración tuteladora, ya se ha dicho en varias ocasiones en este trabajo, se caracteriza por ponerse de perfil en esas circunstancias, a no ser que haya una gran presión social. Esto es lo que hemos denominado «malestar de la Arqueología profesional». Resulta muy deprimente que las habilidades y competencias propias de una profesión no solo no se valoren, sino que, antes bien, se prime su no ejercicio. Por eso se da la paradoja de que las personas con mayor preocupación e interés en realizar excavaciones, que respondan a los estándares académicos o en que se integren vestigios en las nuevas construcciones, lejos de estar cotizados en el mercado laboral, tienen dificultades para encontrar trabajo, como advertía con perplejidad Roig i Buxó (2013: 182 ss.).

La responsabilidad de esta situación recae principalmente sobre la administración tuteladora del patrimonio arqueológico que, estando investida de las competencias otorgadas por el ordenamiento jurídico, ha sido reducida, con la impagable ayuda de un nada desdeñable monto de quienes trabajan en ella, a servir como mera tramitadora de autorizaciones sin capacidad para intervenir en ese ámbito (Rodríguez Temiño 2004: 250 ss.). Quede claro que la relación entre empresas de Arqueología, o arqueólogos profesionales, y promotores se rige por el derecho privado (Roig i Buxó 2013: 182), lo cual supone un obstáculo para que los arqueólogos profesionales sean adalides de iniciativas que van en perjuicio de quienes les han contratado. Sin embargo, la administración cultural tiene la obligación de filtrar qué proyecto debe ser autorizado y cuál no, explicitar las razones de esa negativa, así como fiscalizar mediante las oportunas inspecciones el cumplimiento del proyecto aprobado. Poca duda cabe de que esto no ha sido realizado como debiera en el pasado y, dada la actual falta de recursos, hay muchas posibilidades de que no se haga en el futuro.

Las reflexiones sobre la Arqueología profesional han puesto el punto de mira sobre diversos problemas que la atenazan y los retos más inmediatos a los que se enfrentan no solo los 
profesionales de la Arqueología sino la propia disciplina. Sin embargo, solo mencionaremos aquellos aspectos que podrían mejorarse, e incluso corregirse, con la propuesta que presentamos en el apartado siguiente. Todos han sido reiteradamente advertidos, pero creemos necesario referirlos aquí para poder encajarlos más adelante.

En primer lugar, está la ausencia de titulación específica de arqueólogo en las universidades españolas hasta hace bien poco. Desde la época de la APAE (Querol 1992), este ha sido un caballo de batalla del colectivo profesional y una reivindicación avivada en la segunda mitad de los ochenta y noventa, con la emergencia de las asociaciones profesionales y las secciones de Arqueología de los CDL. Además, en esa época, estaba relacionada con el escaso reconocimiento que los arqueólogos tenían frente a otros profesionales, como los arquitectos, incluso dentro de las propias administraciones ([Grup de treball de la Comisió de Patrimoni] 1992: 57 s.). Más adelante se ha seguido trayendo a colación este hándicap para la delimitación ad origine de quiénes pueden ser considerados como arqueólogos y quiénes no (Domínguez et alii 1994, Vigil-Escalera 2011, Domínguez Alonso 2011, Roig i Buxó 2013 o Benet y Rigo 2015, Vaquerizo Gil 2018: 183 ss.). Sin embargo, la mera posesión de un título universitario no parece suficiente para poder delimitar, a escala nacional, la cualidad de ser arqueólogos profesionales, al menos en los términos en los que en este trabajo lo hemos definido. Entre otras cosas porque no todas las universidades españolas cuentan con esa titulación específica. Por otra parte, la legislación que regula el trabajo en patrimonio arqueológico no acota el perfil profesional de arqueólogo y, así, la inmensa mayoría de quienes en la actualidad ejercen como tales poseen titulaciones en diversas ramas de las humanidades, como Filosofía y Letras o Geografía e Historia.

La segunda cuestión, ya apuntada en el diagnóstico del problema sistémico que vive la Arqueología profesional en España, es el de la salvaje competencia entre profesionales para llevarse los proyectos en liza. Esta se centra más en la disminución de costes económicos que en promover la excelencia profesional y de investigación. Remitimos a lo ya dicho para evitar reiteraciones innecesarias.

Por último, haremos mención del desencuentro generado, como consecuencia de la regulación administrativa de concesión de las autorizaciones de intervenciones arqueológicas, entre la administración y los receptores de tales permisos. El núcleo del malestar de estos últimos, especialmente en el supuesto de que sean arqueólogos profesionales, reside en los tiempos de tramitación y la reiteración de requisitos exigidos. Afortunadamente, esta circunstancia, aunque pudiera extenderse a todo el ámbito nacional, solo presenta un carácter conflictivo en Andalucía, como se expresó con todo lujo de detalles en el referido I Encuentro Estatal de Arqueología Profesional celebrado en Cádiz.

Está lejos de nuestra intención justificar comportamientos administrativos que resultan más que cuestionables, por estar basados en criterios arbitrarios, que nada tienen que ver con la discrecionalidad administrativa. No obstante, sí nos parece adecuado recordar aquí ciertos aspectos de la naturaleza de los procedimientos de autorización de excavaciones, sobre todo por el tiempo de tramitación que conllevan. Sin hacer un detallado análisis del régimen de autorizaciones y sus fundamentos jurídicos (Barcelona Llop 2002, Rodríguez Temiño 2009), pretendemos más bien anotar unas pinceladas sobre su naturaleza prejurídica, que incide en su plasmación en el derecho positivo español.

Desde su instauración en la conocida como Ley de Excavaciones Arqueológicas de 1911, las autorizaciones de actividades arqueológicas han sido una constante en la legislación española sobre patrimonio histórico o cultural. La base de la técnica autorizadora ha variado bien poco: la única modificación ha sido el incremento de documentos y obligaciones exigibles a quienes solicitan ser autorizados para llevar a cabo una intervención. Cabe preguntarse sobre la razón de esta voracidad documental por parte de las administraciones competentes en materia de patrimonio arqueológico.

La razón en esencia, y desprendida de los pormenores, es la siguiente: el monopolio a favor del Estado y sus órganos de gestión para descubrir e investigar nuevos bienes arqueológicos se extendió, como concesión, a otras personas interesadas. Para gestionar de forma adecuada esta ampliación del derecho sobre quiénes podrían excavar más allá de los funcionarios de las administraciones competentes, se instituyó un procedimiento específico que determinase quién era la persona que lo solicita, su competencia en Arqueología 
para desarrollar los trabajos solicitados y la finalidad de esa intervención. Dado que esta competencia resulta de las obligaciones de protección del patrimonio arqueológico encomendadas a la administración cultural, estos requisitos son esenciales para dilucidar la conveniencia o no de autorizar a la persona solicitante.

Retengamos de esta explicación que se trata de procedimientos instituidos para discriminar, entre una población desconocida de eventuales solicitantes, quiénes deben ser acreedores de la autorización. Para ello se requiere documentación acreditativa de estos extremos. Ante la eventualidad de que cualquier persona pueda pedir una autorización para excavaro cualquier otra actividad arqueológica, no cabe otro recurso que pedir documentación, analizarla y resolver en consecuencia.

\section{Una propuesta de solución al malestar de los arqueólogos profesionales}

Nuestra propuesta es la constitución de un cuerpo de Arqueólogos Profesionales de ámbito estatal compuesto por funcionarios en régimen especial, como los notarios; es decir, con régimen funcionarial pero remuneración privada. No es la primera vez que se propone esta solución (Rodríguez Temiño 2004: 258 s.), pero tuvo poco eco ya que fue realizada en el vórtice de la burbuja inmobiliaria, cuando nadie quería oír hablar de regulación. Ahora, además, nos proponemos desarrollarla en sus contenidos básicos y explicar en qué mejoraría la situación actual de los arqueólogos profesionales.

La razón de la existencia de este cuerpo reside en la naturaleza demanial de los bienes arqueológicos (Barcelona Llop 2000). En efecto, los arqueólogos profesionales trabajan sobre bienes de dominio público que pueden verse comprometidos cuando quienes operan sobre ellos dependen de un régimen mercantil libre, como demuestra la experiencia reciente. Son bienes que, además, están destinados a una finalidad asociada a la cultura, entendida como crecimiento intelectual y engrandecimiento personal. Facultades que solo consiguen desplegarse de forma plena cuando se dota a las personasde un conocimiento de la historicidad de los hechos sociales, que les permita una actitud crítica ante las realidades que nos rodean $\mathrm{y}$ de las que formamos parte.
Los arqueólogos profesionales combinan el ejercicio de una función de utilidad pública (la tutela del patrimonio arqueológico a través del registro, conservación y difusión de aquellos bienes que pueden estar en peligro) con una actividad privada (el asesoramiento profesional a los clientes sobre cómo combinar intereses legítimos para usar el suelo con el respeto a los bienes arqueológicos existentes en ese emplazamiento).

Los componentes público y privado de los arqueólogos profesionales reposan en una relación simétrica. Por tanto, deberían articularse ambos para defender los intereses privados de quienes los contratan, pero desde el desempeño de una función pública. No se trata de una mera yuxtaposición o de una mezcla de elementos heterogéneos. Debe tenerse presente que no hay dos funciones, una pública y una privada soldadas con mayor o menor resistencia, sino una interacción de unos elementos en los otros; los componentes públicos (guiados por el interés colectivo predicable del patrimonio arqueológico) deberían penetrar en los privados y moralizarlos. Para ello es fundamental la existencia de una cierta independencia con respecto a los intereses materiales de los clientes. Argumentos similares a estos se predican de la función notarial y de la figura del notario (Rodríguez Adrados 1998, Leña Fernández 2010).

La constitución de este cuerpo dejaría obsoleto el debate sobre quiénes son arqueólogos profesionales, al quedar claro que lo serían quienes pertenezcan al mismo. Otra cosa sería la continuidad de otras personas cuya profesión esté relacionada con la Arqueología, en el sentido explicado al principio de este trabajo. Cabe la duda razonable de si aquellas personas con titulación que les faculte para ejercer como arqueólogas, pero que trabajen por cuenta ajena en empresas de Arqueología, deberían pertenecer o no a este cuerpo. Sería imprudente dar ahora un dictamen, pero en principio cabe pensar que pertenecer al cuerpo y ser contratado «por obra o servicio» no debieran ser situaciones incompatibles.

Lógicamente a un cuerpo así no cabría acceder mediante oposición, sino por mera acreditación de la concurrencia de un determinado número de requisitos (licenciatura o grado en determinadas carreras universitarias, experiencia de trabajo de campo, formación permanente, entre otras condiciones). Además, si el sistema tiene que ser funcional en la regulación 
de la profesión y la gestión de la Arqueología preventiva, el estatus de arqueólogo profesional no debe ser permanente, siendo necesario periódicamente la reacreditación, a fin de mantener los estándares de calidad requeridos.

Del mismo modo, aunque el régimen económico fuese privado, los emolumentos cobrados por los arqueólogos profesionales, al igual que ocurre con notarios o registradores de la propiedad, no dependerían de la voluntad del contratante, sino de los aranceles establecidos. Esto no solo haría más difícil la concurrencia competitiva entre varios profesionales o empresas, sino que también evitaría que el cobro de los salarios dependiese del estado de ánimo de los promotores con respecto de los informes emanados por quienes han contratado. Así, se podría regular, como ocurre con otras profesiones que gozan de ese mismo régimen, el ingreso de los salarios en la caja del colegio de Arqueólogos Profesionales a la firma del contrato con los promotores. Esto asegura que los emolumentos se devenguen una vez finalizados los informes oportunos, tras la excavación o actividad arqueológica pertinente, sin depender de si han sido favorables o no a los intereses de la promotora.

La existencia de un colegio a escala estatal sería más viable una vez acotado el número de quienes sean considerados arqueólogos, sorteando la espada de Damocles de una titulación específica extendida por toda España.

Por último, definidos quiénes son arqueólogos profesionales, los reglamentos de autorización de actividades arqueológicas tendrían que reconocer esta circunstancia mediante la institución de procedimientos abreviados. Mucha de la documentación actualmente exigible habría de ser sustituida por figuras como la declaración responsable apud acta, basadas más en la confianza que en la obligación de discernir sobre la idoneidad de los solicitantes, ante una eventual multitud de peticionarios desconocidos. Para el resto de actuaciones arqueológicas no preventivas seguiría vigente el procedimiento existente.

En definitiva, la existencia de este cuerpo lograría un estatuto jurídico para los arqueólogos profesionales que los blindase frente a la dependencia de los promotores, a la vez que les facilitaría la coparticipación, de forma más abierta, con las administraciones culturales en la tutela de los bienes arqueológicos, pudiendo servir de revulsivo frente a ciertas inercias administrativas.
Obviamente, la eventual existencia de un cuerpo de Arqueólogos Profesionales no resuelve todos los problemas de la Arqueología preventiva, pero estamos convencidos de que sería un paso en la buena dirección porque sí ayudaría a estabilizar su situación laboral.

La idea de un cuerpo de Arqueólogos Profesionales de escala estatal puede parecer un desiderátum inalcanzable o una mera utopía de imposible materialización, a pesar de haber estado presente en las reuniones mencionadas de Cádiz y Madrid. Sin embargo, Francia presenta un ejemplo al que no se ha prestado la debida atención en España.

En efecto, el inicio en este país de la Arqueología de salvamento se materializó en 1973 con la creación de la Association pour les fouilles archéologiques nationales (Afan), una agencia gubernamental dependiente del Ministerio de Cultura encargada de gestionar los fondos estatales destinados a las excavaciones de urgencia y que, con el tiempo, fue también recurriendo a las aportaciones de índole privada. Ciertamente este modelo estatalizado sufrió una crisis enorme, que provocó manifestaciones de arqueólogos a finales de los ochenta (Bellet 1992). La Afan fue objeto de escrutinio público, a partir del denominado «affaire de Rodez», donde se destruyó buena parte de un yacimiento urbano sin las excavaciones oportunas (ver el artículo «Privés de fouilles, les archéologues se révoltent. A Rodez, l'aval de Juppé, donné à un projet immobilier, met le feu aux poudres» en Liberation de 21 de enero de 1997). Obviamente, el creciente neoliberalismo de las décadas pasadas hizo mella en la Arqueología preventiva francesa hasta tal punto que el futuro de las excavaciones preventivas fue tratado en las cámaras legislativas en 2001. Como consecuencia, al socaire de los postulados de la Convención de La Valetta (1992), se creó el Institut national de recherches archéologiques préventives (Inrap). Este fue reformado en 2003 para permitir la concurrencia de empresas de Arqueología privadas, museos y servicios arqueológicos municipales (Rodríguez Temiño 2004: 268 ss.). Este proceso culminó en 2007 cuando la concurrencia competitiva tomó carta de naturaleza (Demoule 2010). Sin embargo, a partir de 2016, con la aprobación de una nueva ley relativa a la libertad de creación, a la arquitectura y al patrimonio, que reforma el libro $\mathrm{V}$ del Code du Patrimoine dedicado a la Arqueología, esta ha vuelto a reagruparse en torno a la agencia esta- 
tal y el Estado parece haber asumido de nuevo su papel de regulador y ordenador del sector.

En nuestro caso, no sería preciso una reforma de la Ley de Patrimonio Histórico Español de 1985 que contemplase la Arqueología preventiva, ya suficientemente regulada en la legislación infraestatal, sino una ley que crease el mencionado cuerpo de Arqueólogos Profesionales. Llevar al Parlamento y al Senado la situación de los arqueólogos profesionales nos ayudaría a sacarnos de la invisibilidad en la que vivimos con respecto al resto de la sociedad.

Muy posiblemente, en el supuesto de la creación de ese cuerpo, los resultados no serían del agrado de todos los profesionales, pero sin duda habría merecido la pena recorrer el camino. El principal reto no es encontrar eco en los partidos políticos con representación parlamentaria, sino conseguir un consenso previo entre todas personas que nos dedicamos a la Arqueología de manera profesional, esta vez usada esta expresión sensu lato. Una propuesta de esta naturaleza solo resultará creíble al resto de la sociedad y, por tanto, para quienes nos representan políticamente si asciende desde abajo, desde el colectivo formado por quienes tienen la Arqueología presente de alguna forma en su actividad laboral.

En este artículo hemos evitado voluntariamente acotar más determinados aspectos de orden práctico, o dar respuesta a muchos interrogantes que pueden suscitarse al leer la propuesta presentada. No es este el momento oportuno para esas disquisiciones. Como dice la frase atribuida a Julio César, «Cuando lleguemos a ese río, cruzaremos ese puente». En todo caso, cuando sea pertinente afrontar ese reto, deberán ser arqueólogos profesionales quienes lideren y manejen los hilos de ese debate y no los autores de este trabajo, aunque nos prestemos con toda nuestra mejor voluntad a colaborar a llegar al río y cruzar el puente.

\section{Notas}

1. Kobayashi Maru es el nombre de una prueba de simulación a la que se someten los cadetes de la Flota Estelar en el universo ficticio de Star Trek, mencionada por vez primera en Star Trek: The Wrath of Khan (1982). Tiene como objetivo el eventual rescate de la nave civil averiada Kobayashi Maru, que se encuentra localizada en zona neutral klingon. La entrada de cualquier nave de la Flota Estelar supondría la violación de los tratados de paz y, por tanto, un acto de guerra. Si la opción elegida es la de ayuda, tres naves klingon atacarán y destruirán inevitablemente a la nave del simulador. Si se decide no prestar ayuda, la misión se considerará un fracaso. El equipo cadete debe decidir si rescatar a la tripulación de la nave afectada, aun arriesgando su propia nave y sus vidas, o abandonar al Kobayashi a su destrucción. El sentido de la prueba es aleccionar a los cadetes de la posibilidad de escenarios donde es imposible vencer.

\section{Referencias bibliográficas}

Ad'AC [Associació d'Arqueólegs de Catalunya] (2000): Necessitat i objetius de la creació d'una associació d'arqueòlegs professionals a Catalunya. Revista d'Arqueologia de Ponent, 10: 366-367.

Aitchison, K. (2012). Breaking New Ground: how archaeology works. Landward Research. London. Edición de Kindle.

Almansa Sánchez, J. (2014). Bendita crisis, maldita profesión. Arqueoweb, 15: 322-325.

- (2017). Arqueología y Sociedad: Interacción y Acción desde la Teoría Crítica. [Tesis doctoral] Universidad Complutense de Madrid. Madrid.

Álvarez Martínez, V. (2011): Agotados de esperar el Futuro. El futuro de la arqueología (J. Almansa Sánchez, ed.). JAS Arqueología, Madrid: 1-7.

Aparicio Resco, P. (2018). Mercenarios es la selva del precariado: contruyendo la arqueología virtual como profesión. Congreso Nacional de Arqueología Profesional (Zaragoza 2017) (J. I. Lorenzo Lizalde, ed.). CDL de Aragón, Zaragoza: 19-26.

Ayers, B. (2002): People and places: archaeological approaches to urban change. An English view. Archeologia e urbanistica (A. Ricci, a cura di). Edizioni all'Insegna del Giglio, Florencia: 183-197.

Barcelona Llop, J. (2000): El dominio público arqueológico. Revista de Administración Pública, 151: 133165. 
- (2002): Aspectos del régimen jurídico de las autorizaciones arqueológicas. Revista Aragonesa de Administración Pública, 21: 113-146

Barreiro Martínez, D. (2013): Arqueológicas. Hacia una arqueología aplicada. Ediciones Bellaterra S. L., Barcelona.

Bellet, M. (1992): La situation professionelle de l'archéologie en France. I Jornades sobre la situació professional en l'arqueologia (Barcelona, 1987). Col·legi Oficial de Doctors i Llicenciats en Filosofia i Lletresi en Ciéncies de Catalunya, Barcelona: 143152.

Benet Arqué, C. i Rigo Jovells, A. (2015): La professió d'arqueòleg i l'activitat arqueològica des del punt de vista d'una empresa. Evolució i actualitat. Pyrenae, 46(2): 125-138.

Berrocal Ruiz, P. (2014): Arqueología Profesional Liberal y de Empresa. Saguntum. Papeles del Laboratorio de Arqueología de Valencia, Extra 15: 99-104.

Bishop, M.; Collis, J. and Hinton, P. (1999): A future for archaeologist: professional training and carrier structure in Archaeology. The Archaeologist, 35: 14-16.

Chitty, G. (1999): Training in Professional Archaeology: a preliminary review. Hawkshead Archaeology \& Conservation, London.

Chowne, P. (1998): The Museum of London and the Changing nature of Archaeology in London. II Simposio Internacional de Museos de Ciudad (Barcelona 1995). Museo de la Ciudad de Barcelona, Barcelona: 169-176.

CNT-Córdoba. Sección Sindical de Arqueología (2010). Córdoba, una arqueología en precario (I). El Convenio Gerencia Municipal de Urbanismo-Universidad de Córdoba. Antiquitas, 22: 253-269.

- (2011). Córdoba, una arqueología en precario (II). La arqueología de mercado y la destrucción de los Arrabales Occidentales. Antiquitas, 23: 245-270.

[Grup de treball de la Comisió de Patrimoni] (1992): Informe del grup de treball laboral de la Comissió de Patrimoni del Col-legi de Doctors i Llicenciats en Filosofia i Lletres i en Ciencies de Catalunya (Barcelona, juliol 1985). I Jornades sobre la situació professional en l'arqueologia (Barcelona, 1987). Col·legi Oficial de Doctors i Llicenciats en Filosofia i Lletresi en Ciéncies de Catalunya, Barcelona: 57-60.

Dalwood, H. (1987): What is professional archaeology? Field Archaeology, 7: 104-105.

Darvill, T.; Atkins, M. (1991): Regulating archaeological work by contract, Technical paper, 8, Birminghan.

Darvill, T. and Russell, B. (2002): Archaeology after PPG16: archaeological investigations in England 1990-1999. Bournemouth University and English Heritage, Bournemouth and London.

Demoule, J. P. (2010): The crisis-economic, ideological, and archaeological. Archaeology and the global economic crisis. Multiple impacts, possible solutions (N. Schanger \& K. Aitchison, eds.). Culture Lab Éditions, Tervuren: 13-18.

Díaz del Río Español, P. (1996): El código ético de la Asociación Europea de Arqueólogos. La situación madrileña. Apuntes de Arqueología, 5: XV.

- (2000): Arqueología Comercial y Estructura de Clase. Gestión Patrimonial y Desarrollo Social (M. Bóveda, coord). CAPA 12. Universidad de Santiago de Compostela, Santiago de Compostela: 7-18.

Domínguez Alonso, R. M. (2011): De aquellos barros, estos lodos. El futuro de la arqueología (J. Almansa Sánchez, ed.). JAS. Arqueología, Madrid: 73-78.

Domínguez, R.M.; Fernández, A.; Herce, J. L.; Menasanch, M.; Presas, M. (1994): Empresas de arqueología y arqueología urbana: investigación, negocio, profesión. Arqueología y Territorio Medieval, 1: 8392.

Dreyfus, H. and Dreyfus, S. (1986): Mind over machine. The Power of Human Intuition and Expertise in the Era of the Computer. Basil Blackwell, Oxford.

Dromgoole, S. (2004): Murky waters for government policy: the case of a 17th century Britishwarship and 10 tonnes of gold coins. Marine Policy, 28: 189-198.

Everill, P. (2012): The Ivisible Diggers - A Study of British Commerical Archaeology. Oxbow Books, Oxford.

Fernández-Miranda, M. (1985). Modelo arqueológico y patrimonio histórico. Análisis e Investigaciones Culturales, 24: 27-36.

Fitting, J.E. (1997): Economia i arqueologia. Intervenció i Patrimoni, 1: 67-71.

[Grup de treball de la Comisió de Patrimoni] (1992): Informe del grup de treball laboral de la Comissió de Patrimoni del Col·legi de Doctors i Llicenciats en Filosofia i Lletres i en Ciencies de Catalunya (Barce- 
lona, juliol 1985). I Jornades sobre la situació professional en l’arqueologia (Barcelona, 1987). Col·legi Oficial de Doctors i Llicenciats en Filosofia i Lletresi en Ciéncies de Catalunya, Barcelona: 57-60.

Leña Fernández, R. (2010). La función pública notarial. Academia Sevillana del Notariado, 21: 405-441.

Lineros Romero, R. (2001). Arqueología urbana en Carmona: teoría y práctica. Carmona romana (A. Caballos Rufino, ed.). Universidad de Sevilla y Ayuntamiento de Carmona, Sevilla: 517-526.

Marín Suárez, C. (2011): Diario de campo. El futuro de la arqueología (J. Almansa Sánchez, ed.). JAS. Arqueología, Madrid: 151-157.

Martín-Bueno, M. (2018). Patrimonio Arqueológico: ciencia, administraciones, profesión. Congreso Nacional de Arqueología Profesional (Zaragoza 2017) (J. I. Lorenzo Lizalde, ed.). CDL de Aragón, Zaragoza: 27-31.

Martín Mompeán, J.L.; Morín de Pablos, J.; Penedo Cobo, E.; Ramírez Molina, E.; Urbano Gutiérrez, A. (1997): La visión del modelo madrileño desde el enfoque profesional. Apuntes de Arqueología, 6: $27-$ 29.

Masclans Latorre, A. (2011): Arqueología, Recortes y Precariedad en Catalunya. El futuro de la arqueología (J. Almansa Sánchez, ed.). JAS. Arqueología, Madrid: 157-162.

McGill, G. (1995): Building on the Past. A guide to the archaeology and development process. E \& FN Spon, London.

Mena Muñoz, P.; Méndez Madariaga, A.; Velasco Steigrad, F. (1997): El modelo madrileño, Apuntes de Arqueología, 6: XIII.

Moya Maleno, P. R. (2010): Grandezas y miserias de la arqueología de empresa en la España del siglo XXI. Complutum, 21(1): 9-26.

Morín de Pablos, J.; Barroso Cabrera, R., (2014): De la arqueología de la mortadela a la arqueología de la resistencia. La democratización fallida de la Arqueología española. Arqueoweb, 15: 315-321.

Parga Dans, E. (2009): El Mercado del Patrimonio: nacimiento, estructura y desarrollo de las empresas que gestionan el patrimonio arqueológico. CAPA 21. CASIC, Santiago de Compostela.

- (2010): Commercial archaeology in Spain: its growth, development, and the impact of the global economic crisis. En N. Schanger \& K. Aitchison, eds.: 45-54.

Petit, D. (1991) : Crise social ou crise épistemologique? Revista d'Arqueologia de Ponent, 1: 307-310.

Querol, M. Á. (1992): El estatuto profesional de la arqueología. I Jornades sobre la situació professional en l'arqueologia (Barcelona, 1987). Col·legi Oficial de Doctors i Llicenciats en Filosofia i Lletresi en Ciéncies de Catalunya, Barcelona: 107-112.

- (2000): Una empresa llamada arqueología. Revista d'Arqueología de Ponent, 10: 253-264.

—; Martínez Navarrete, M. I.; Hernández Hernández, F.; Cerdeño, L.; Antona Val, V. (1995): The value of archaeological heritage: an analysis by the Professional Association of Spanish Archaeologists (APAE). Journal of European Archaeology, 3(1): 233-247.

Raab, L.M. (1997): Arribar a la professionalitat a través de la fragmentació ètica: advertències davant l'arqueologia orientada al client. Intervenció i Patrimoni, 1: 5566.

Radin, M. J. (1993): Reinterpreting Property. University of Chicago Press, Chicago (IL).

Ribera i Lacomba, A. (2015): El incierto pasado reciente de la arqueología valenciana. Pyrenae, 46(2): 121-123.

Rodríguez Adrados, A. (1998). Los componentes públicos de la función notalia. Revista Jurídica del Notariado, 25: 55-84.

Rodríguez Temiño, I. (2001): Formarse con el quehacer diario. PH Boletín del Instituto Andaluz de Patrimonio Histórico, 37: 38-39.

- (2004): Arqueología urbana en España. Ariel, Barcelona.

- (2009): Notas sobre la regulación de las actividades arqueológicas. Patrimonio Cultural y Derecho, 13 : 87-116.

- (2010a): Arqueología urbana en tiempos de crisis. Arqueología, patrimonio histórico y urbanismo en las ciudades Patrimonio de la Humanidad de España. Actas de las Jornadas Técnicas sobre Arqueología, Patrimonio Histórico y Urbanismo (Tarragona 2009). Grupo de Ciudades Patrimonio de la Humanidad de España, Tarragona: 17-29.

- (2010b): Repensar la arqueología urbana. Anuari d'Arqueologia i Patromoni de Barcelona 2009. Ajuntament de Barcelona, Barcelona: 15-25.

—; Rodríguez de Guzmán Sánchez, S. (1997): Excavaciones arqueológicas en Andalucía: 1984-1995. Trabajos de Prehistoria, 54(1): 57-70. 
Roig i Buxó, J. (2013). Trabajo, mercado y conocimiento. La arqueología como profesión. La materialidad de la historia. La arqueología en los inicios del siglo XXI (J. A. Quirós Castillo, ed.). Akal, Madrid: 177-200.

Ruiz Rodríguez, A. (1989): De las arqueologías a la Arqueología. 1978-1988 Andalucía: Diez años de Cultura. Junta de Andalucía, Sevilla: 11-17.

Salvatierra Cuenca, V. (1994): Historia y desarrollo del Modelo Andaluz de Arqueología. Trabajos de Prehistoria, 51(1): 1-13.

- (2004): Arqueología urbana. Investigación y profesión. Anales de Arqueología Cordobesa, 15: 45-59.

- (2013): En los adentros de la ciudad. Arqueología y urbanismo. La materialidad de la historia. La arqueología en los inicios del siglo XXI (J. A. Quirós Castillo, ed.). Akal, Madrid: 241-270.

Schanger, N. \& Aitchison, K. (eds.) (2010): Archaeology and the global economic crisis. Multiple impacts, possible solutions. Culture Lab Éditions, Tervuren.

Schön, D. A. (1983): The Reflective Practitioner. How Professionals Think in Action. Basic Books, Inc, New York

Swain, H. (ed.) (1991): Competitive Tendering in Archaeology. Hertford.

Tynjälä, P. (999): Towards expert knowledge? A comparison between a constructivist and a traditional learning environment in the university. International Journal of Educational Research, 31: 357-442

Valdés Fernández, F. (1989): La arqueología urbana como concepto. Reflexiones sobre la gestión del patrimonio arqueológico madrileño. Curso de formación de jóvenes en arqueología urbana (1987). Gobierno Vasco, San Sebastián: 1720.

Vaquerizo Gil, D. (2018): Cuando (no siempre) hablan «las piedras». Hacia una arqueología integral en España como recurso de futuro. Reflexiones desde Andalucía. JAS Arqueología, Madrid.

Velasco Steigrad, F. (1992): Un modelo de gestión a partir de la declaración de zonas arqueológicas amplias: el caso de Madrid. Jornadas Internacionales de Arqueología de Intervención (San Sebastián, 1991). Gobierno Vasco, Bilbao: 7584. 